\title{
A practical study of the hepatic vascular system anatomy of the caudate lobe
}

\author{
Wei Mao $^{1 \wedge}$, Xinhua Jiang ${ }^{1}$, Yong Cao ${ }^{1}$, Shaojun Xiong ${ }^{1}$, Yihua Huang ${ }^{1}$, Leiming Jiao ${ }^{1}$, Hee Jung Wang ${ }^{2}$ \\ ${ }^{1}$ Department of General Surgery, Nanchang University Infectious Disease Hospital, Nanchang, China; ${ }^{2}$ Department of Surgery, Ajou University \\ School of Medicine, Suwon, South Korea
}

Correspondence to: Hee Jung Wang. Department of Surgery, Ajou University School of Medicine, Suwon, South Korea. Email: wanghj@ajou.ac.kr.

\begin{abstract}
Background: This study aimed to examine the inflow and outflow vascular system of the caudate lobe and determine its relevance to hepatobiliary surgery.

Methods: A total of 41 cadaveric liver specimens were dissected in 2019 to evaluate the inflow and outflow vascular system of the caudate lobe.

Results: The Glisson's pedicles of the paracaval portion were mainly from the right pedicle in 14 cases $(34.15 \%)$, mainly from the left pedicle in 22 cases $(53.66 \%)$, and equally from the left and right pedicle in 5 cases (12.19\%). Many thick branches of the portal vein were found behind the plane consisting of the hilar plate and Arantius ligament, but none of them were thicker than $1 \mathrm{~mm}$ in front of the plane. All of the veins of the caudate lobe drained into the inferior vena cava (IVC) via the anterior face. There was an avascular zone without short hepatic veins (SHVs) consisting of loose connective tissue between the retrohepatic IVC and caudate lobe, with its length and width being 45-97 $\mathrm{mm}$ and 6-15 $\mathrm{mm}$, respectively.

Conclusions: The plane consisting of the hilar plate and Arantius ligament can be regarded as the boundary between the caudate lobe and the other lobes. There is an avascular zone without SHVs consisting of loose connective tissue between the retrohepatic IVC and caudate lobe.
\end{abstract}

Keywords: Caudate lobe; retrohepatic inferior vena cava (retrohepatic IVC); anatomy

Submitted Jun 20, 2020. Accepted for publication Nov 03, 2020.

doi: 10.21037/qims-20-780

View this article at: http://dx.doi.org/10.21037/qims-20-780

\section{Introduction}

The caudate lobe is a protuberance of irregular shape which lies in the dorsal sector of the liver. This protuberance is generally referred to as "Spiegel's lobe", after Spiegel who first described it in 1627. In 1954, Couinaud studied a number of liver specimens and divided the liver into eight segments, designating the caudate lobe as segment I. In 1989, Couinaud proposed that the caudate lobe be divided into two parts: the left Spiegel lobe, designated as segment I; and the right part encompassing the paracaval portion, designated as segment IX (1). In 1990, Nimura proposed that segment IX be divided into two parts according to the blood supply (2). Currently, a consensus has been reached, and the caudate lobe is commonly divided into three regions: the left Spiegel lobe (Couinaud's segment I), the paracaval portion (segment IX), and the caudate process (segment X) (3). The left Spiegel lobe, the prominent part of the caudate lobe, is located on the left of the inferior vena cava (IVC) and underneath the lesser omentum. The paracaval portion lies on the right sector of the caudate lobe, posterior and inferior to the middle and right hepatic veins in the front of and surrounding the IVC from the anterior face. The caudate process lies between the right

^ ORCID: 0000-0002-7594-8686. 
portal vein and the IVC, just to the right of the paracaval portion connected with the right liver lobe, and sometimes appears as a half-free protuberance.

The caudate lobe is an independent lobe with a special anatomical location and complex structure. It spreads to the hilum posterior and inferior to the bifurcation of the portal vein, lies posterior to the portal pedicle and segment IV, V and, VIII, and lies anterior to the retrohepatic IVC; to its left is the left lobe of the liver, while its right is connected with the right lobe with no specific mark (4). The characteristic vascular system of the caudate lobe is highly variable, which makes dealing with it complex and challenging. It has blood flow from both the left and, to a lesser extent, the right portal systems. Venous supply takes place along its posterior part directly into the IVC via the short hepatic veins (SHVs) of variable numbers and sizes. Caudate biliary drainage occurs mainly via the left hepatic duct, but it also involves small tributaries to the right, while hepatic arterial flow is mostly via a solitary branch from the main left hepatic artery.

Because of its particular anatomical location and variable and intricate vascular system, surgery of the caudate lobe is very difficult and considered a high risk for intraoperative complications. Accordingly, a hepatobiliary surgeon must be familiar with its vascular system and common variation types, especially in isolated lobectomy, donor liver procurement in living-donor liver transplantation, or liver hanging maneuver. Surprisingly, there have been few reported studies about surgical approaches for caudate lobe resection.

\section{Methods}

To study the vascular system of the caudate lobe, we dissected 41 cadaveric liver specimens at Ajou University in May to August 2019. All of the liver specimens were harvested from cadavers without hepatic disease, soaked in $10 \%$ formalin, and the caudate lobes within were carefully dissected with scalpel, scissors, and vascular clamp. The parenchyma was then removed from the lobe to reveal all of the vascular system inside the caudate lobe. Next, the posterior face of the retrohepatic IVC was cut open to reveal its structure, and then the data regarding the amounts, lengths, diameters, positions, and origins were collected and analyzed. This study was approved by the Ethics Board of Nanchang University Infectious Disease Hospital.

\section{Results}

The portal blood supply of the caudate lobe can typically be described as follows: the portal blood supply of the Spiegel lobe originates from near the superior border of the left portal vein, while that of the caudate process starts from the posterior branch of the right portal vein or is absent. The portal supplies to the paracaval portion are generally more variable; they mostly originate from near the superior border of the right portal vein, although they occasionally begin from the anterior branch of the right portal vein or from the left portal vein (Figure 1). In this study, it was found that the portal veins of the paracaval portion were mainly from the right pedicle in 14 cases (34.15\%), mainly from the left pedicle in 22 cases $(53.66 \%)$, and equally from both pedicles in 5 cases (12.19\%) (Figure 2).

There are few reports that describe the paracaval portion in detail. In this study, we suggested the line between the corner part of the left portal vein and the left margin of the IVC as the left boundary of the paracaval portion (Figure $3 A$ ) and the line between the bifurcation of the right portal vein and the right margin of the IVC as the right boundary of the paracaval portion (Figure 3B).

In our previous study, we proposed the right and ventral margin of the caudate lobe (5). In the present study, we proposed a plane consisting of the hilar plate and Arantius ligament as the ventral margin of the caudate lobe; many thick and strong branches of the portal vein were found behind the plane, but none were thicker than $1 \mathrm{~mm}$ in front of the plane (Figure 4).

The venous drainage of the caudate lobe that we observed was as follows: all of the veins of the caudate lobe drained anteriorly into the IVC and often assumed short extrahepatic vascular features such as thin walls, and variable numbers and locations. The number of SHVs were 4-16, with an average of 8.61. The length of the retrohepatic IVC was $5-10 \mathrm{~cm}$. Either 1 or 2 thick veins, $5-10 \mathrm{~mm}$ in diameter, drained from segment VI and/or segment VII, known as the inferior right hepatic vein (IRHV). There was also an avascular zone without SHVs consisting of loose connective tissue between the retrohepatic IVC and the caudate lobe, with its length and width being 45-97 and 6-15 mm, respectively (Tables 1 and 2).

\section{Discussion}

The portal blood supply of the caudate lobe is very 

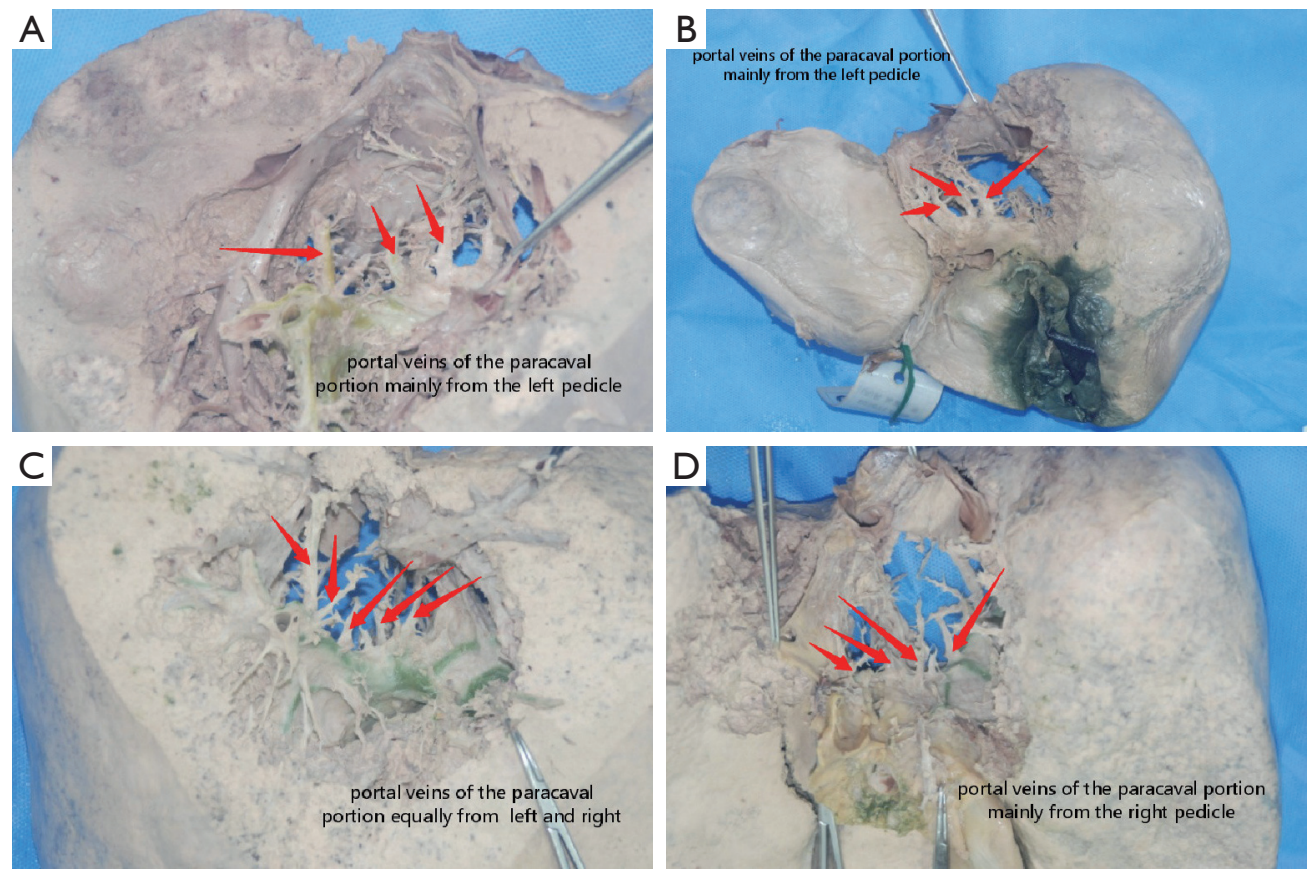

Figure 1 The portal vein of the paracaval portion. The arrows indicate the portal veins of the paracaval portion.

A

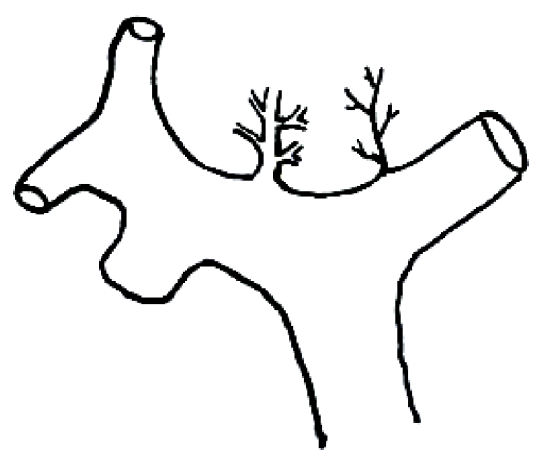

Portal veins of the paracaval portion mainly from the right pedicle (34.15\%)
B

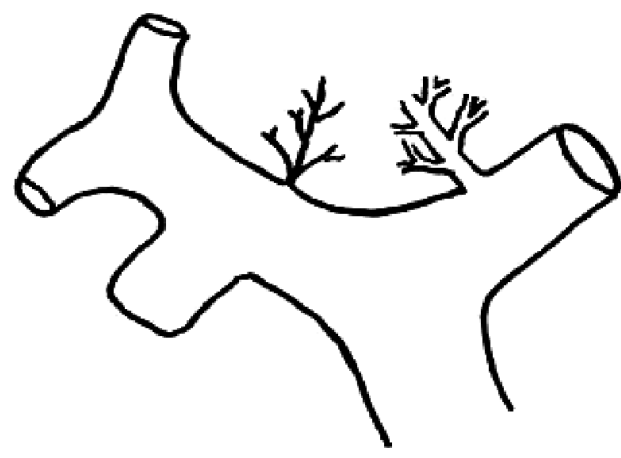

Portal veins of the paracaval portion mainly from the left pedicle

(53.66\%)
C

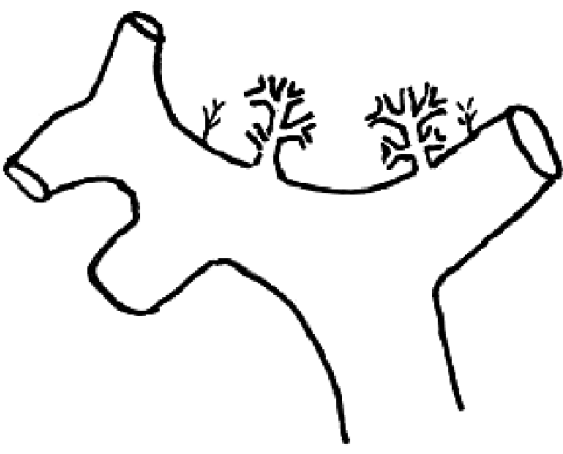

Portal veins of the paracaval portion equally from the left and right pedicles (12.19\%)

Figure 2 The portal veins of the paracaval portion.

important in liver surgery. Commonly, the portal blood supply of the Spiegel lobe originates from near the superior border of the left portal vein, and that of the caudate process begins from the posterior branch of the right portal vein, or is absent. The portal supply of the paracaval portion is the most important, and it is generally more variable (6-8).
It predominantly originates from near the superior border of the left or right portal vein, although it occasionally starts from the anterior branch of the right portal vein.

During the fetal period, the umbilical vein flows into the IVC directly, atrophies, occludes 2-3 months after birth, and forms the round and Arantius ligaments (9). In 

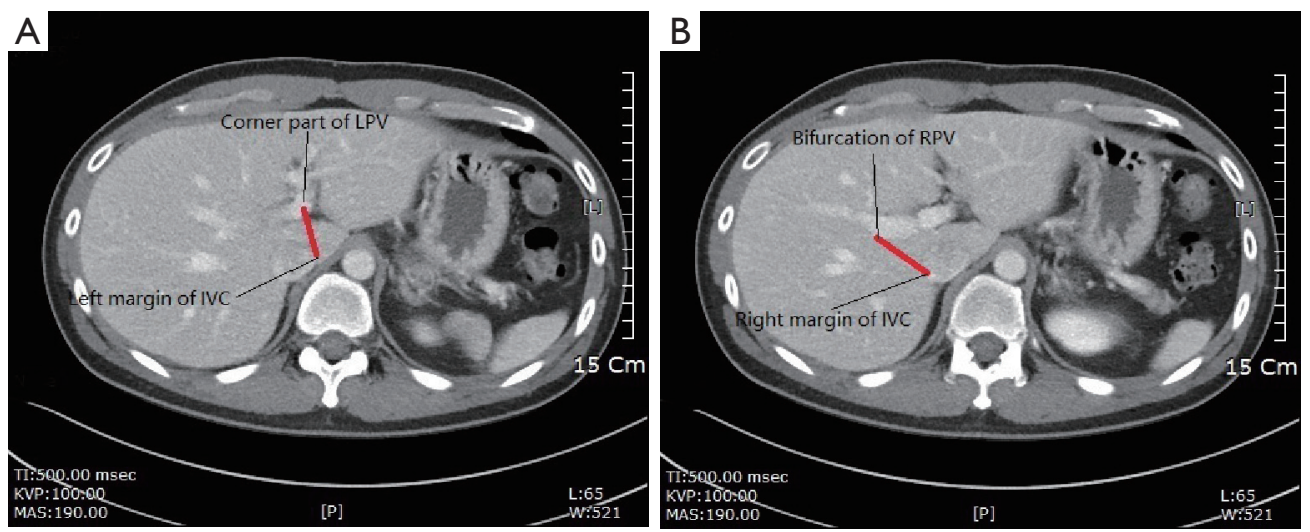

Figure 3 The left and right boundary of the paracaval portion. (A) The left boundary of the paracaval portion; (B) the right boundary of the paracaval portion. IVC, inferior vena cava; LPV, left portal vein; RPV, right portal vein.

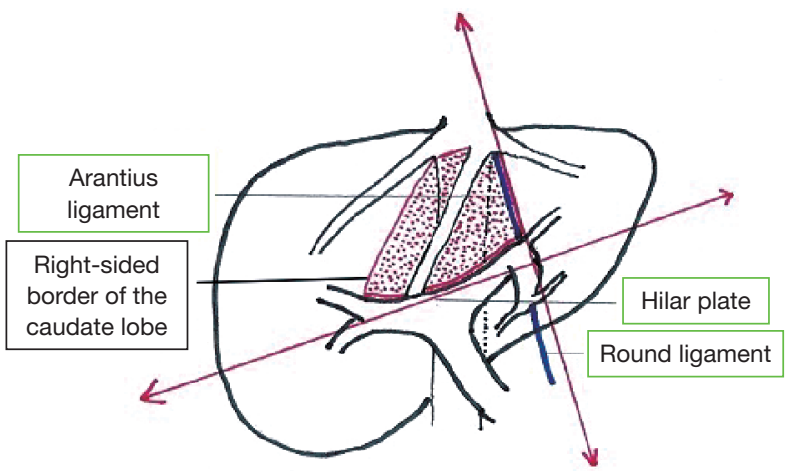

Figure 4 The plane consisting of the hilar plate and Arantius ligament.

the present study, we found that there were many thick branches of the portal vein behind the panel but none of these branches were thicker than $1 \mathrm{~mm}$ in front of the plane. Therefore, we suggest that the plane consisting of the hilar plate and Arantius ligament be regarded as the boundary between the caudate lobe and other lobes.

Due to its particular location in the liver and its independent vascular system, surgery associated with the caudate lobe is difficult and highly risky (10). With the development of three-dimensional (3D) technology, precision surgical technology has been widely used, and $3 \mathrm{D}$-printed models provide a great added value to clinical practice (11). Indeed, the most challenging part is the paracaval portion: owing to the paracaval portion's unique location in the dorsal sector adjacent to the right and middle hepatic veins, not only must all of the SHVs be reliably dealt with, but the IVC and hepatic vein must also be carefully protected. Additionally, the surgery must be carried out under direct vision, the SHVs should be inferiorly-to-superiorly severed along the retrohepatic IVC seriatim, and some thick SHVs should be sutured soon after being severed to minimize hemorrhage. Although, there are generally no SHVs on the anterior face of the IVC, neoplasm vessels occasionally drain into the IVC (12), which should be considered during the surgery. Multiple anatomical variations were observed in the SHVs; the SHV's had an average of 5-12 branches, drained into the IVC from different directions, and some tiny SHVs also drained into the middle and left hepatic veins (13-15).

There were a number of SHVs that drained the caudate lobe, while others drained the posterior lobe that is inferior to the right hepatic veins (IRHV) (16). In addition, multiple anatomical variations of the IRHV were observed, often displaying a thick diameter and low confluent position.

Liu et al. have reported the occurrence rate of IRHVs with an average of $1-8 \mathrm{SHV}$ s to be $87.2 \%$ (17), which is consistent with the $84 \%$ occurrence rate reported by Dai et al. (18). There is a relationship between IRHV and the right hepatic vein: the thicker the IRHV, the thinner the right hepatic vein, and vice versa. We divided the IRHV into three groups: the superior IRHV, median IRHV, and inferior IRHV. In this study we found that the occurrence rate of IRHV was 75.61 , and the average diameter was $6.76 \mathrm{~mm}$. Thick IRHVs mainly drained into the venous blood of segments VI and VII, but became shallower as they approached the IVC.

In 1989, Couinaud found that there is a clearance without SHVs consisting of loose connective tissue between the retrohepatic IVC and the caudate lobe, suggesting 
Table 1 Short hepatic veins and inferior right hepatic vein

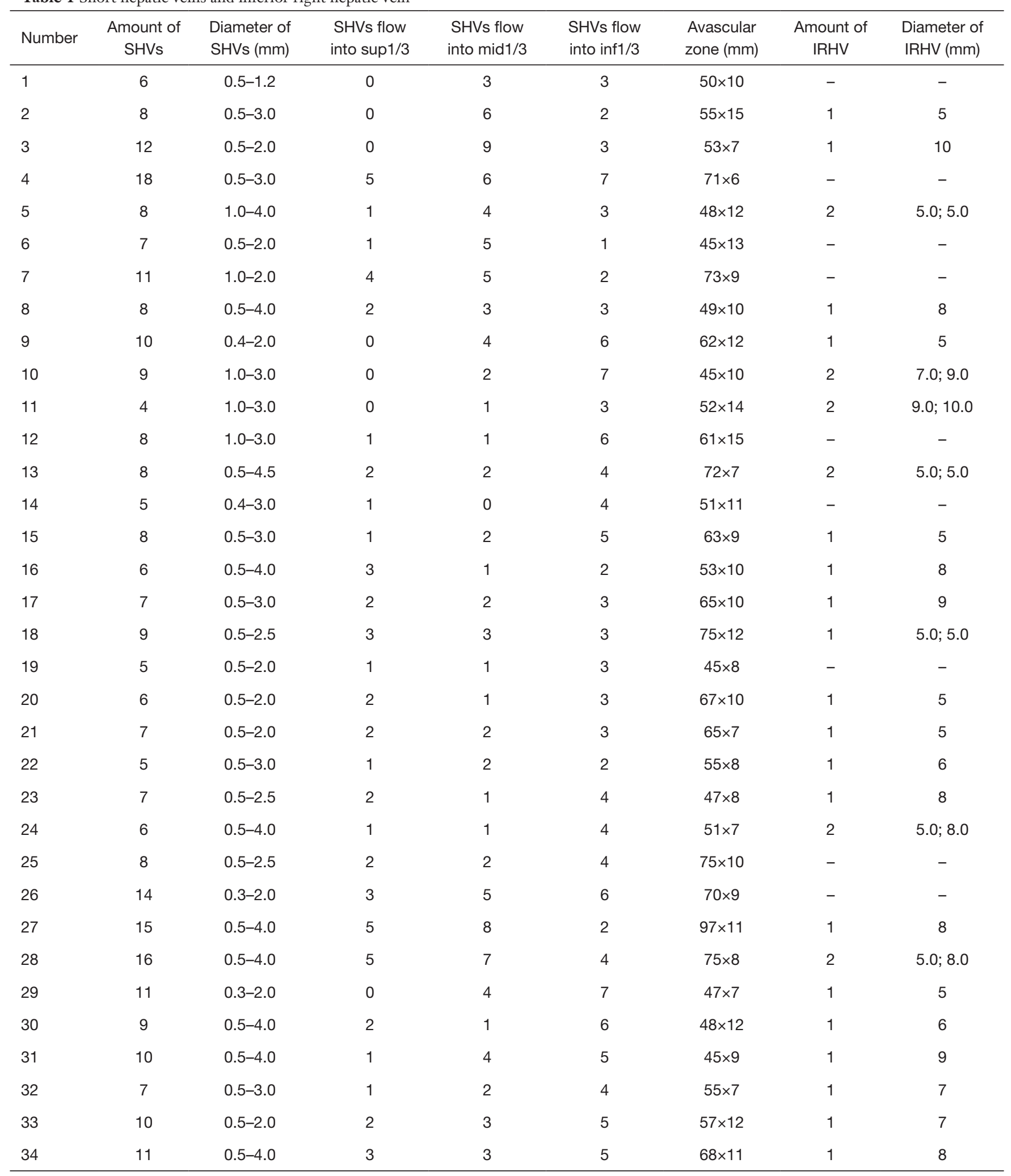

Table 1 (continued) 
Table 1 (continued)

\begin{tabular}{|c|c|c|c|c|c|c|c|c|}
\hline Number & $\begin{array}{c}\text { Amount of } \\
\text { SHVs }\end{array}$ & $\begin{array}{l}\text { Diameter of } \\
\text { SHVs (mm) }\end{array}$ & $\begin{array}{l}\text { SHVs flow } \\
\text { into sup1/3 }\end{array}$ & $\begin{array}{l}\text { SHVs flow } \\
\text { into mid1/3 }\end{array}$ & $\begin{array}{l}\text { SHVs flow } \\
\text { into inf } 1 / 3\end{array}$ & $\begin{array}{l}\text { Avascular } \\
\text { zone }(\mathrm{mm})\end{array}$ & $\begin{array}{l}\text { Amount of } \\
\text { IRHV }\end{array}$ & $\begin{array}{l}\text { Diameter of } \\
\text { IRHV (mm) }\end{array}$ \\
\hline 35 & 7 & $0.5-3.0$ & 2 & 1 & 4 & $59 \times 9$ & 1 & 7 \\
\hline 37 & 8 & $0.5-4.0$ & 1 & 3 & 4 & $65 \times 10$ & 1 & 6 \\
\hline 40 & 8 & $0.5-3.0$ & 1 & 1 & 6 & $67 \times 12$ & - & - \\
\hline 41 & 7 & $0.5-3.0$ & 0 & 3 & 4 & $78 \times 10$ & 1 & 7 \\
\hline Average & 8.61 & $0.546-2.980$ & $19.55 \%$ & $34.56 \%$ & $45.89 \%$ & $59.976 \times 9.829$ & $75.61 \%$ & 6.757 \\
\hline
\end{tabular}

SHVs, short hepatic veins; IRHV, inferior right hepatic vein.

Table 2 Portal vein of the paracaval portion

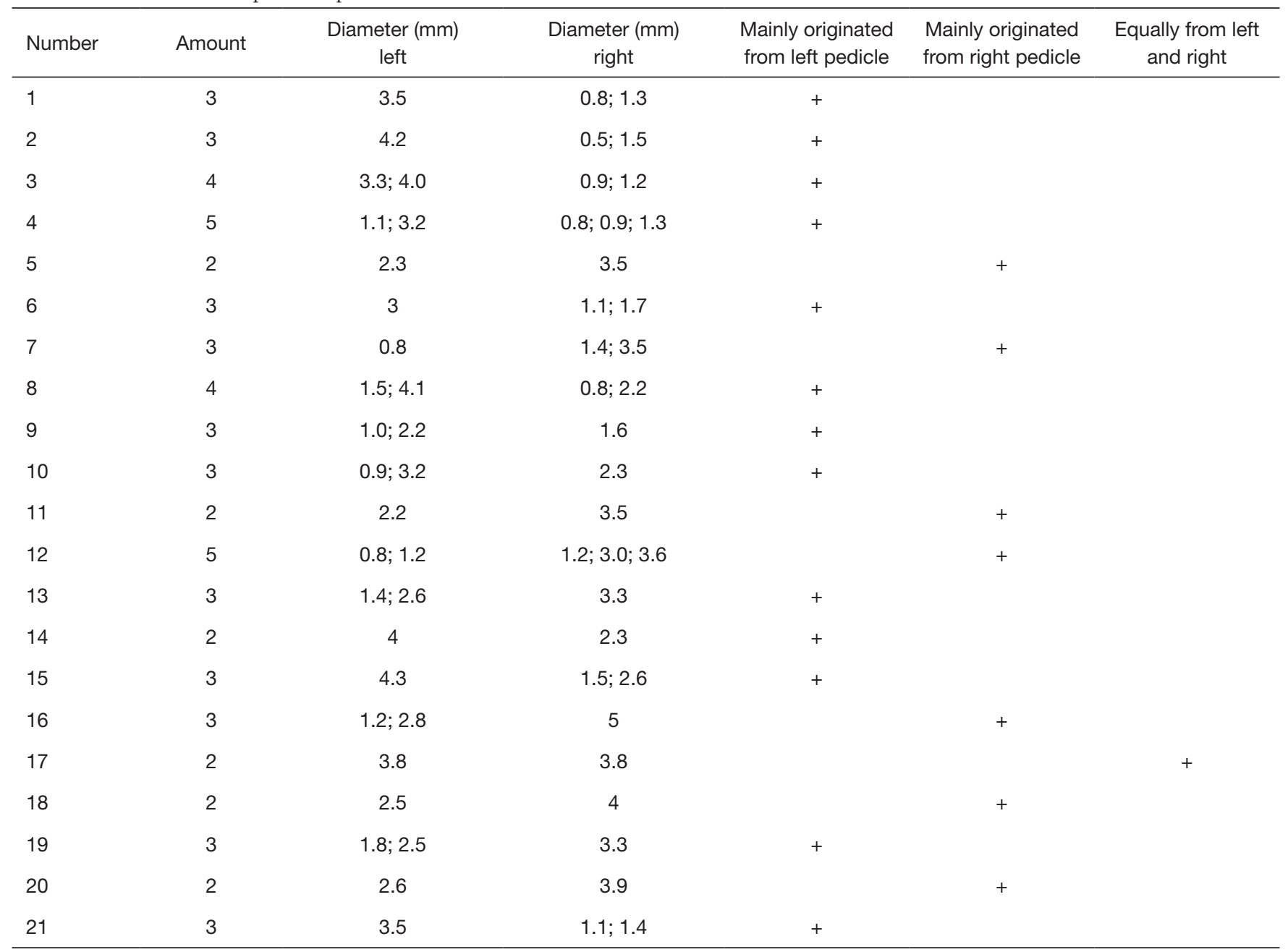

Table 2 (continued) 
Table 2 (continued)

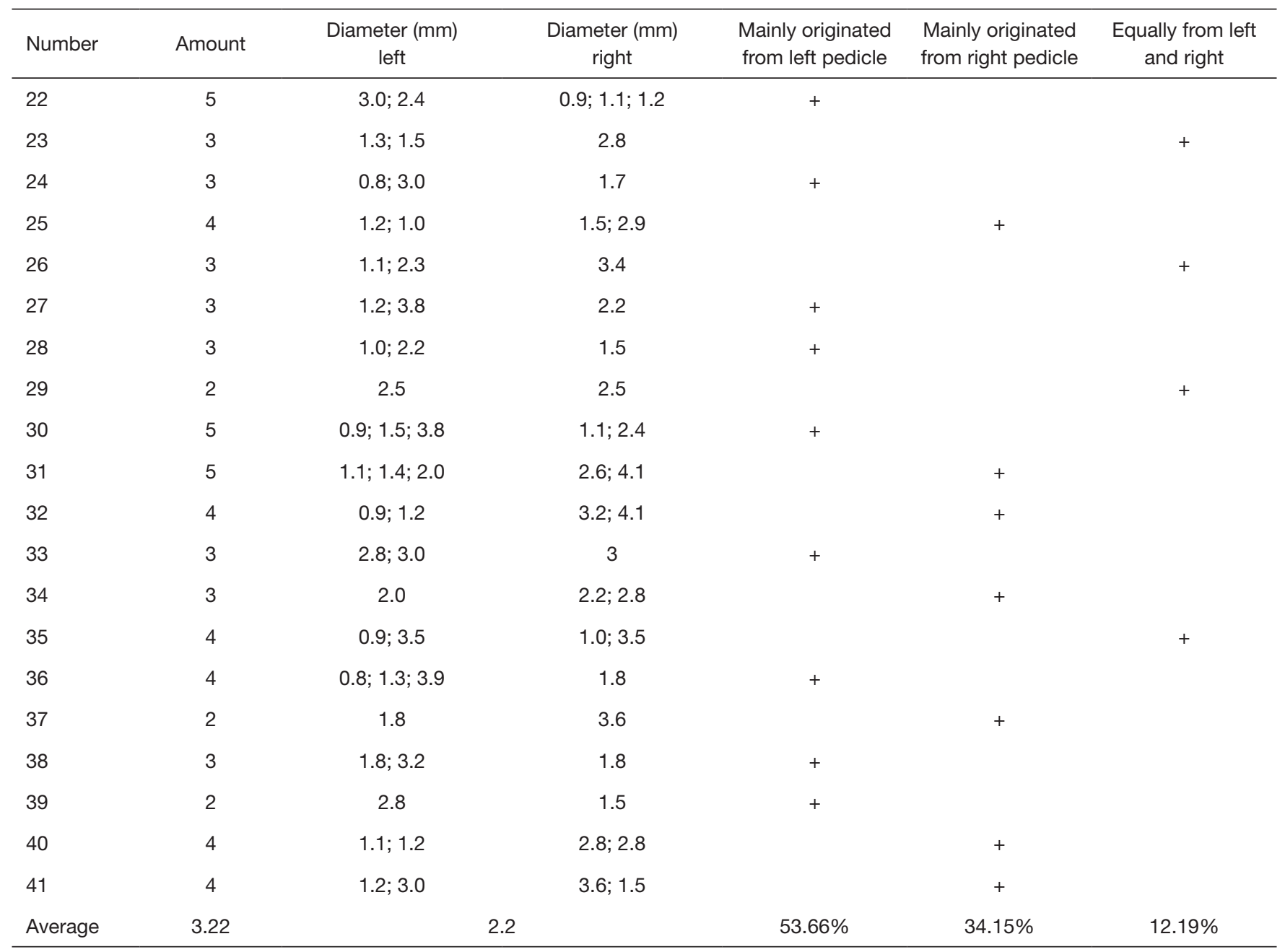

that there is an avascular zone without SHVs (19). Sato and Meng reported a clearance width of 5-15 $\mathrm{mm}$ and a length of 4.1-7.8 cm $(15,20)$. Later, in 2001, Belghiti et al. reported a liver hanging maneuver in a complicated liver neoplasm (21) in which they placed a springy band through the clearance, hung the liver, and successfully performed right hemihepatectomy from an anterior approach. The hanging maneuver has a very minimal hemodynamic influence, making it especially suitable for complicated hepatectomy and donor liver procurement in living-donor liver transplantation. We measured the length and width of the avascular zone and determined that they were 40-78 and $5-15 \mathrm{~mm}$, respectively, with an average of 59.976 and $9.829 \mathrm{~mm}$, respectively.

Liver surgery has now become a routine procedure, and a hepatobiliary surgeon should be very familiar with the anatomical structure and common variation types, particularly when performing caudate lobectomy, donor liver procurement in living-donor liver transplantation, and liver hanging maneuver. Therefore, we present the results of our research with emphasis on their significance to hepatobiliary surgeons.

\section{Acknowledgments}

All the authors express their deep gratitude to the innominate cadaveric donors. We thank them for their contribution to the medical and health fields, and have learned a great deal from their donations.

Funding: None. 


\section{Footnote}

Conflicts of Interest: All authors have completed the ICMJE uniform disclosure form (available at http://dx.doi. org/10.21037/qims-20-780). The authors have no conflicts of interest to declare.

Ethical Statement: This study was approved by Ethics Board of Nanchang University Infectious Disease Hospital.

Open Access Statement: This is an Open Access article distributed in accordance with the Creative Commons Attribution-NonCommercial-NoDerivs 4.0 International License (CC BY-NC-ND 4.0), which permits the noncommercial replication and distribution of the article with the strict proviso that no changes or edits are made and the original work is properly cited (including links to both the formal publication through the relevant DOI and the license). See: https://creativecommons.org/licenses/by-nc-nd/4.0/.

\section{References}

1. Couinaud C. Dorsal sector of the liver. Chirurgie 1998;123:8-15.

2. Nimura Y, Hayakawa N, Kamiya J, Kondo S, Shionoya S. Hepatic segmentectomy with caudate lobe resection for bile duct carcinoma of the hepatic hilus. World J Surg 1990,14:535.

3. Murakami G, Hata F. Human liver caudate lobe and liver segment. Anat Sci Int. 2002;77:211-24.

4. Yan LN. Hepatic surgery. People's Medical Publishing House. 2002;7:13-4.

5. Shen XY, Wang HJ, Kim BW, Hong SY, Kim MN, Hu XG. Can we delineate preoperatively the right and ventral margins of caudate lobe of the liver? Ann Surg Treat Res 2019;97:124-9.

6. Kogure K, Kuwano H, Yorifuji H, Ishikawa H, Takata $\mathrm{K}$, Makuuchi M. The caudate processus hepatic vein: a boundary hepatic vein between the caudate lobe and the right liver. Ann Surg 2008;247:288-93.

7. Takayama T, Midorikawa Y, Higaki T, Nakayama H, Moriguchi M, Aramaki O, Yamazaki S, Aoki M, Kogure K, Makuuchi M. Algorithm for resecting hepatocellular carcinoma in the caudate lobe. Ann Surg 2019. doi: 10.1097/SLA.0000000000003384.

8. Maki H, Sakamoto Y, Kawaguchi Y, Akamatsu N, Kaneko J, Arita J, Hasegawa K, Kokudo N. Anatomical Boundary
Between the Caudate Lobe of the Liver and Adjacent Segments Based on Three-Dimensional Analysis for Precise Resections. J Gastrointest Surg 2018;22:1709-14.

9. Arkadiusz K, Maciej K, Tomasz G, Aleksandra S, Anna K. Modern Ultrasonography of the Umbilical Cord: Prenatal Diagnosis of Umbilical Cord Abnormalities and Assessment of Fetal Wellbeing. International Medical Journal of Experimental and Clinical Research 2019;25:3170-80.

10. Qiu ZQ, Tan WF, Yan PN, Luo XJ, Zhang BH, Wu MC, Jiang XQ, Lau WY. Early control of short hepatic portal veins in isolated or combined hepatic caudate lobectomy. Hepatobiliary Pancreat Dis Int 2012;11:377-82.

11. Gómez Ciriza G, Gómez Cía T, Rivero Belenchón I, Valverde Pérez I. Quality and accuracy of 3D printed models in medicine. Quant Imaging Med Surg, 2019;9:1475-6.

12. Zuo HQ, Yan LN, Zeng Y, Yang JY, Luo HZ, Liu JW, Zhou LX, Jin Q. Caudate lobectomy by the third porta hepatic anatomical method: a study of 16 cases. Hepatobiliary Pancreat Dis Int 2006;5:387-90.

13. Nakamura S, Tsuzuki T. Surgical anatomy of the hepatic veins and the inferior vena cava. Surg Gynecol Obstet 1981;152:43-50.

14. Mehran R, Schneider R, Franchebois P. The minor hepatic veins: anatomy and classification. Clin Anat 2000;13:416-21.

15. Sato TJ, Hirai I, Murakami G, Kanamura T, Hata F, Hirata K. An anatomical study of short hepatic veins, with special reference to delineation of the caudate lobe for hanging maneuver of the liver without the usual mobilization. J Hepatobiliary Pancreat Surg 2002;9:55-60.

16. Kanamura T, Murakami G, Hirai I, Hata F, Sato TJ, Kumon M, Nakajima Y, High dorsal drainage routes of Spiegel's lobe. J Hepatobiliary Pancreat Surg 2001;8:549-56.

17. Liu SW, Wang HJ, Xu WX. The anatomy of the inferior right hepatic veins of the liver. Chin J Surg 1991;29:708-10.

18. Dai YH, Ji QY, Liu JH. An anatomical study of human hepatic veins. Chin J Surg 1988;26:568-71.

19. Couinaud C. Surgical anatomy of the liver revisited $\mathrm{Ch} 4$. Anatomy of the dorsal sector of the liver. New considerations on liver anatomy. Paris: Pers Ed, 1989:26-39.

20. Meng WCS, Shao CX, Mak KL, Lau PYY, Yeung YP, Yip 
AWC. Anatomical justification of Belghiti's liver hanging maneuver in right hepatectomy with anterior approach. ANZ J Surg 2003;73:407-9.

21. Belghiti J, Guevara OA, Noun R, Saldinger PF,

Cite this article as: Mao W, Jiang X, Cao Y, Xiong S, Huang Y, Jiao L, Wang HJ. A practical study of the hepatic vascular system anatomy of the caudate lobe. Quant Imaging Med Surg 2021;11(4):1313-1321. doi: 10.21037/qims-20-780
Kianmanesh R. Liver hanging maneuver: a safe approach to right hepatectomy without liver mobilization. J Am Coll Surg 2001;193:109-11. 